\title{
Simulation: An Effective Marketing Tool
}

\author{
Ashu Gupta \\ Sr. Lecturer \\ Apeejay Institute of Management, \\ Jalandhar, Punjab, India.
}

\author{
Dr. Kawaljeet Singh \\ Director, University Computer \\ Centre, Punjabi University, \\ Patiala, Punjab, India.
}

\author{
Dr.Rajesh Verma \\ Assistant Professor \\ Lovely Professional Univ, \\ Phagwara, Punjab, India.
}

\begin{abstract}
Simulation- the study and use of models of complex relationships- is one of the most valuable techniques in the management sciences, and has been greatly advanced in the last decade by the use of high-speed computers. Following the extensive development of simulations of military systems and the advent of high-speed computers, there has been, in recent years, a growing interest in applying simulation techniques to business problems including marketing problems. This paper presents a literature review of application of computer simulation in marketing and demonstrates the advantages of simulation as an effective marketing tool. The design of computer simulation for the industrial buying process which focuses on the buyers and their response to various marketing strategies, is described as a generalized-microanalytic-interactive-simulation. Also, the role of simulation in marketing game is discussed.
\end{abstract}

Keywords

Simulation; Marketing; Model; Decision; Game

\section{INTRODUCTION}

Simulation- the study and use of models of complex relationships- is one of the most valuable techniques in the management sciences, and has been greatly advanced in the last decade by the use of high-speed computers. Simulation is being widely used for modeling and analysis of systems in various application areas such as manufacturing, construction, transport, logistics, communication networks, health care, military etc. Following the extensive use of simulations in various area and the advent of high-speed computers, there has been in recent years, a growing interest in applying simulation techniques to business problems including marketing problems. Simulation can be used for industrial buying process. The complexity of the buying process, the large number of purchase determinants and the heterogeneity of purchase situations requirements can be studied using simulation technology. This paper presents a literature review of application of computer simulation in marketing and demonstrates the advantages of simulation as an effective marketing tool. The design of computer simulation of the industrial buying process which focuses on the buyers and their responses to various marketing strategies is described as a generalized-microanalytic-interactive-simulation. Also the role of simulation as marketing management game is discussed.

\section{REVIEW OF LITERATURE}

Simulations have been applied to many areas of marketing management. For example, alternative physical distribution and inventory management strategies have been evaluated by Shycon and Maffie (1960), Kuehn and Hamburger (1963), and Robinson (1958). A classic study by Cyert et al. (1963) simulated pricing and retail ordering decisions of executives in a large department store, and a similar study of the pricing-decision process by marketing executives in a large manufacturing firm was made by Howard and Morgenstern (1975). Both of the latter studies had an impressive predictive accuracy.

Simulation techniques have also been applied to advertising problems. The Simulmatics Corporation (1962) developed a simulation model to estimate the exposure value of any given media plan and also developed a behavioral simulation model of the advertising communication process. Forrester (1959) also simulated different timing patterns of advertising expenditure to study the effect of timing on product and inventory stability.

Apart from these simulations of a single marketing decision area, there has been a 
growing interest in simulation models of the total marketing system. Amstutz (1967) micro-analytic market simulation is one of the most comprehensive of its kind. It includes complete models of the behavior of consumers, distributors, retailers and salesmen in making purchase decisions in media and word-of-mouth communication in brand image formation etc. Kotler (1965) has also used a computer simulation to evaluate the results associated with the use of different marketing strategies by two companies introducing a new product simultaneously. Simulation can also be used to gain a better generic understanding of the phenomenon studied. According to Balderston and Hoggatt (1964), simulation of the lumber market was primarily aimed at studying the complex relationships of the market structure rather than at evaluating marketing strategies.

\section{SIMULATION IN MARKETING}

Simulation, according to Orcutt (1960), is the general approach to the study and use of models. More specifically, Balderston and Hoggatt (1964) defined simulation as the construction of "models which show the working of very complex relationships- those which are too complex to be reduced to simple conclusions by means of mathematical or statistical analysis, or ordinary reasoning."

Simulation is, then, one of the most valuable management science techniques for examining complex problems, and is well suited to solving marketing problems, since marketing phenomenon tend to be highly complex and dynamic in character. This complexity stems from three major sources;

- $\quad$ First, most marketing problems require the consideration of a large number of interrelated variables and environmental conditions.

- Secondly, there is frequently a high element of uncertainty. Whether this uncertainty is due to the actions of competitors or other uncontrollable variables, it increases the difficulty of making sound marketing decisions.

- $\quad$ Finally, the lack of relevant information frequently hinders the capacity of executives to understand and therefore to predict and control the market for their company's product.
Simulation techniques have been applied to many aspects of marketing management. Their widespread use is reflected in the current marketing literature. For example, marketing research texts such as Green and Tull (1966) and Frank and Green (1967) devote considerable attention to the users and techniques of simulation.

Three major uses or applications of these techniques for marketing management may be distinguished:

1. as an aid in decision making

2. as a means for gaining further insight into a system and as a guideline for research

3. for operational gaming in a business exercise or game

As a marketing operational game, the simulation may provide a flexible computer-based training device suitable for demonstration of the anatomy of the industrial buying process and tests of its sensitivity to marketing inputs. This may help identify and diagnose buying determinants and their timing under realistically modeled conditions. As an aid for industrial buying, the simulation can assist industrial purchasers in the evaluation and design of their buying organization by stressing the effects of the existing organizational conditions on their own buyers' performance. The simulation will also serve as a guideline for future research, to assure a concentration of research in areas where potential results seem to be important to the understanding of industrial buying behavior.

The major participants in an industrial marketing system and the interactions among them are summarized in Figure 1. As illustrated in this figure, the manufacturer/marketer may interact with salesmen, distributors and both users and buyers of the buying organization. Similarly manufacturer/salesmen may interact with the manufacturer, distributors and the various members of the buying organization. The distributors as well as their salesmen may also interact with the other participants in the marketing system. The various interactions in the marketing system may involve transfers of policy statements and promotional information, orders, payments, performance feedback information, and product and service flows. 


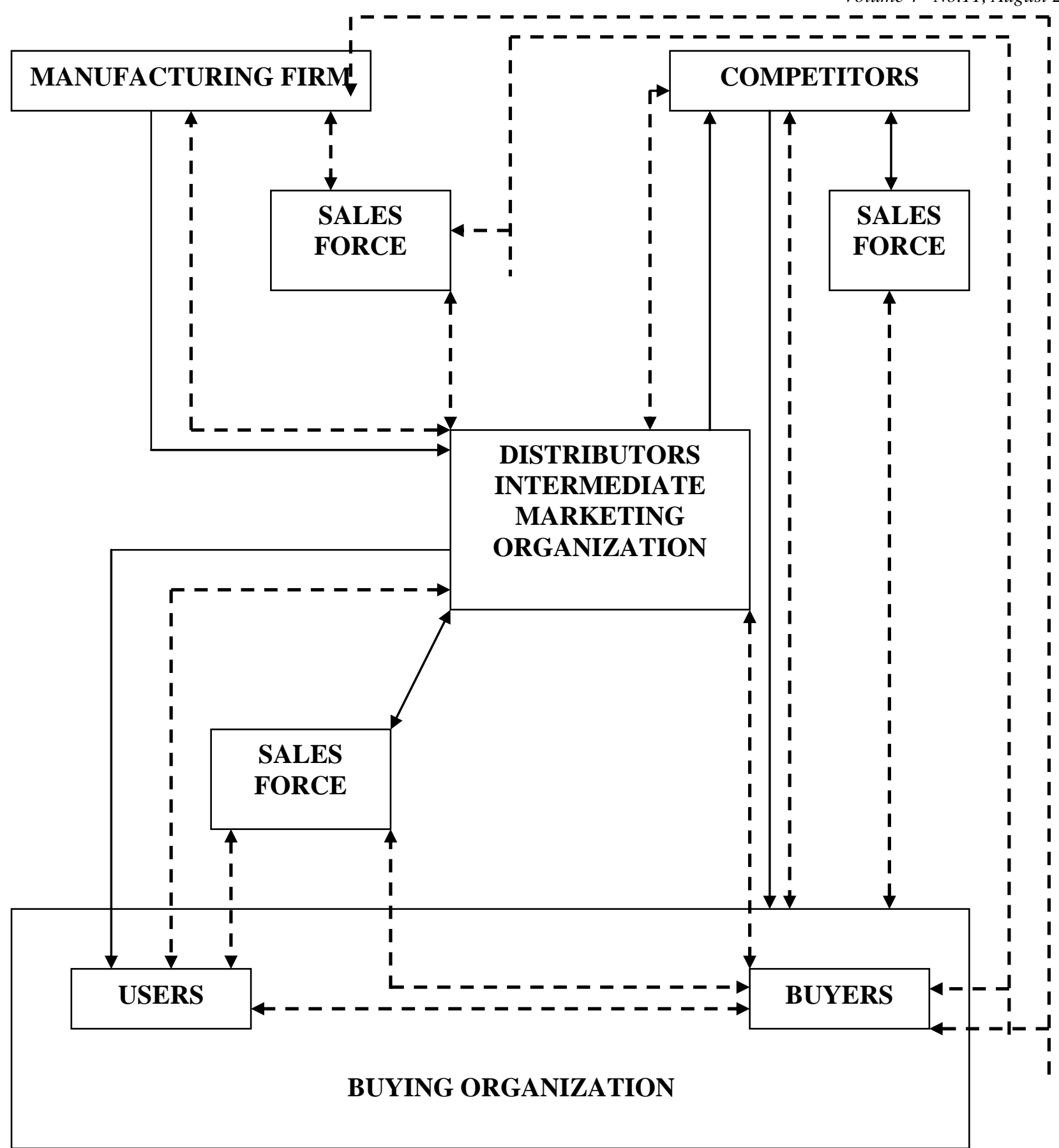

Figure 1: A Macro Structure of an Industrial Marketing System

Product Flow

Information Flow
At the core of the marketing system is the buying organization, the focal point of the whole marketing process. Effective industrial marketing strategies require knowledge of the buyer's behavior- his decision processes, buying motives and relevant forces, which affect his behavior. It is the industrial buyer's decision process and probable response to various marketing variables that is the core of the industrial buying simulation.

\section{DESIGN OF THE SIMULATION}

The computer simulation of the industrial buying process which focuses on the buyers and their responses to various marketing strategies, can be described as a generalizedmicroanalytic-interactive-simulation.

1. Generalized-The term is used to describe the general nature of the simulation. It does not suggest the applicability of the simulation to all industrial buying situations. On the contrary, the simulation in its 
present form is probably not applicable to any specific industrial buying situation. It does provide, however, a generalized guideline for the construction of appropriate simulations for specific markets and firms i.e. it provides a methodology that can be adapted to various situations, and the types of data needed for the construction of specific simulations. As a "demonstration piece" the simulation lacks many of the features that a specific simulation would have (Robinson, 1957). Yet its generalized nature can still be useful in better understanding the industrial buying process and in providing a framework for the design of specific industrial buying simulations.

2. Microanalytic- The term is used to describe a complex system simulation made up of relatively simple components. This approach to the design of a simulation combines the advantages of parsimonious representation of microstructures with the ability to handle highly complex microstructures (Claycamp and Amstutz, 1968). More specifically, Amstutz (1967) has stated that the advantages of a microanalytic simulation are largely a function of its behavioral content. By encompassing knowledge and assumptions regarding behavior within the market, it provides a means of relating management actions to purchase behavior. While an aggregate model may generate correct answers at a point in time, it provides little or no insight into the reasons for these answers. The microanalytic simulation has the potential to provide right answers for the right reasons.

3. Interactive- The user is an active participant in the simulation. A number of decisions, such as whether reciprocity plays a role in given industry and hence should be considered in the purchasing process, have to be made by the user of the simulation. This participation enables tailoring the simulation to a variety of situation.

\section{SIMULATION AS A DECISION AID}

The principal use of computer simulation in marketing management is to reproduce marketing behavior in an artificial environment, in order to evaluate the implications of alternative marketing strategies, and to observe the probable effect of changes in external variables on that behavior. Used in this way, simulation models enable marketing managers to conduct experiments on a model instead of experimenting with the real market in the real world. Alternative courses of action can be simulated, over a range of probable values of parameters under different assumed environmental conditions, to observer the results of such choices. Different initial assumptions about the format of the relationships within the model can also be made, to test their impact on these results, and in particular on that result associated with the "best" course of action (as projected by the model).

The major advantages of simulation models are, therefore, their ability to examine alternative marketing strategies rapidly, relatively cheaply, without requiring the actual commitment of resources. Ideally, this examination is done under realistic conditions, with a realistic model- indeed, the accuracy of representation of actual behavior depends entirely on the accuracy of the original description of the system.

\section{SIMULATION AS A MARKETING GAME}

Simulations in the form of business games have often been used as training or educational devices. As Green and Tull (1966) observed that simulations have sometimes been quite useful as training devices for demonstrating the interaction of many variables on the game's output and giving the player some feel for the impact of other's decisions on the results of his own decisions. Marketing games, therefore, enable marketing managers to obtain realistic experience in decision making and the analysis of strategies, and to understand and appreciate the interaction of competitive behavior in a simulated environment.

A particularly comprehensive operational game which simulated the interaction of up to five oil-company service stations, has been developed and a special-purpose computer and laboratory have been designed and built for playing it (Robinson, 1961). One of the unique features of this simulation was its continuous operation, which permitted administrative interventions as often or as seldom as individual participants chose.

The Total Market Environment Simulation (TOMES) which is probably one of the most detailed and comprehensive simulations of an entire marketing system, is currently being used as marketing game (Amstutz and Claycamp, 1964). It contains populations of consumers, retailers, distributors and salesmen. The consumer model alone comprises over 1000 decisionmaking units. Participants in the game manage competing companies in the simulated environment and have to make a number of marketing decisions. They can vary product characteristics, place individual advertisements in specific media, use direct or indirect distribution etc., and thus gain valuable experience in making marketing decisions.

The judicious application of computer simulation to marketing phenomenon, as an aid to decision-making, to research or to teaching, can be of considerable value in improving managerial understanding of, and ability to, handle complex marketing problems. Such simulations can ultimately help in selecting and evaluating alternative marketing strategies, and thus lead to improvements in decision making and the success of management policy.

\section{CONCLUSIONS}

Marketing planning often requires the analysis of complex systems involving a large number of inter-related factors. Even after reasonable simplifications they can not easily be handled by traditional analytic techniques. It is to deal with such situations that analysts have had recourse to simulation models.

Industrial buying situations are no exception to the general complexity and heterogeneity of market planning. A microanalytic-interactive simulation of industrial buying has been developed as an aid to industrial market planners in the analysis, evaluation and planning of marketing and buying activities. Development of simulation is still in progress. But even at its present relatively crude stage, the simulation has achieved its prime objective of demonstrating the feasibility of, and potential for, developing a computer simulation of marketing strategies. 


\section{REFERENCES}

[1] Amstutz, A. E. 1967. Computer Simulation of Competitive Market Response. Cambridge: The MIT Press.

[2] Amstutz, A. E., \& Claycamp, H. J. 1964. The Total Market Environment Simulation: An Approach to Management Education. Industrial Management Review, 5(2): 46-60.

[3] Balderston, F. E., \& Hoggatt, A. 1964. Simulating Market Processes. In R. L. Day (Ed.), Marketing Models (pp.29-39). Scranton, Pennsylvania: International Textbook Company.

[4] Claycamp, H. J., \& Amstutz, A. E. 1968. Simulation Techniques in the Analysis of Marketing Strategy. In F. M. Bass et al. (Eds.), Applications of the Sciences in Marketing Management (pp. 47-48). New York: John Wiley \& Sons.

[5] Cyert, R. M., March, J. G., \& Moore, C. C. 1963. A Specific Price and Output Model. In R. M. Cyert and J. G. March (Eds.), A Behavioral Theory of the Firm (pp. 128-48). Englewood Cliffs, NJ: Prentice Hall.

[6] Forrester, J. W. 1959. Advertising: A Problem in Industrial Dynamics. Harvard Business Review, 37(2): 100-110.

[7] Green, P. E., \& Tull, D. S. 1966. Research for Marketing Decisions, Englewood Cliffs, NJ: Prentice Hall.

[8] Howard, J. A., \& Morganroth, W. M. 1975. A Positive Model of Executive Decisions. Management Science, 5(1): 21-27.
[9] Kotler, P. 1965. Competitive Strategies for New Product Marketing Over the Product Life Cycle. Management Science, 12(2): 104-119.

[10] Kotler, P. 1967. Operations Research in Marketing. Harvard Business Review, 45(1): 70-79.

[11] Kuehn, A. A., \& Hamburger M. J. 1963. A Program for Locating Warehouses. Management Science, 9: 643-646.

[12] Orcutt, G. H. 1960. Simulation of Economic Systems. The American Economic Review, 1(5): 893-907.

[13] Robinson, P. J. 1958. A Report on Simulation in Marketing. First System Simulation Symposium. New York: American Institute of Industrial Engineers.

[14] Robinson, P. J. 1961. The Use of Analogue Computers in Operational Games. In J. Kibbee et al. (Eds.), Management Games (pp. 80-86). New York: Reinhold.

[15] Robinson, P. J. 1967. Cases in Simulation: A Research as a Management Demonstration Piece. In A. Shuchman (Ed.), Scientific Decision Making in Business Readings in Operations Research for Nonmathematicians (pp. 425-434). New York: Holt, Rinehart and Winston Inc.

[16] Simulmatics Corporation. 1962. Simulmatics Media Mix: Technical Description. New York.

[17] Skycon, H. M., \& Maffie, R. B. 1960. Simulation Tool for Better Distribution. Harvard Business Review, 4: 21-41. 